\title{
Monitoring of the physical health state among 16-17-year-old female students
}

\author{
Oleksandr Mozolev \\ Department of Theory and Methodology of Physical Culture and Valeology, \\ Khmelnytskyi Humanitarian and Pedagogical Academy, Khmelnytskyi, Ukraine
}

\section{abstract}

Background: The results of monitoring the physical health of 16-17-year-old girls who became first-year students of Khmelnytskyi Humanitarian-Pedagogical Academy during 2016-2019 have been analysed in the article.

Material and methods:

1670 female students participated in the research. In the course of the research, the number of people belonging to the main, preparatory and special medical group was determined, as well as those who were exempted from attending physical education classes.

Results: The results of the research have found that there is a tendency for an increase in the number of female students exempted from attending physical education classes from $3.17 \%$ to $6.60 \%$, and the increase in the number of female students assigned for health reasons to special medical groups at physical education classes from $6.57 \%$ to $11.93 \%$.

Conclusions: The analysis of changes of anthropometric indicators of girls showed that there is a growing number of overweight female students from $9.2 \%$ to $11.7 \%$, and from $1.2 \%$ to $1.7 \%$ of those who have $1-2$ degree of obesity. The analysis of functional indicators of physical condition showed that $21.8 \%$ of female students had deviations in age-related heart rate, and the indicator of vital capacity of lungs in $34.8 \%$ of female students was lower than the established norm. An analysis of the Robinson index showed that the level of energy potential of female students tends to deteriorate

Key words: physical health, monitoring, female students, anthropological indicators, morphological resources.

\section{article details}

Article statistics: Word count: 3,103; Tables: 4; Figures: 0; References: 20

Received: April 2020; Accepted: April 2021; Published: September 2021

Full-text PDF: http://www.balticsportscience.com

Copyright @ Gdansk University of Physical Education and Sport, Poland

Indexation: Celdes, Clarivate Analytics Emerging Sources Citation Index (ESCI), CNKI Scholar (China National Knowledge Infrastructure), CNPIEC, DOAJ, EBSCO - Central \& Eastern European Academic Source, EBSCO - SPORTDiscus, EBSCO Discovery Service, Google Scholar, Index Copernicus, J-Gate, Naviga (Softweco, Primo Central (ExLibris), ProQuest - Family Health, ProQuest - Health \& Medical Complete, ProQuest - Illustrata: Health Sciences, ProQuest Nursing \& Allied Health Source, Summon (Serials Solutions/ProQuest, TDOne (TDNet), Ulrich's Periodicals Directory/ ulrichsweb, WorldCat (OCLC)

Funding: This research received no specific grant from any funding agency in the public, commercial, or not-for-profit sectors.

Conflict of interests: Author has declared that no competing interest exists. $\begin{aligned} \text { Corresponding author: } & \text { Oleksandr Mozolev, Department of Theory and Methodology of Physical Culture and Valeology of Khmelnytskyi } \\ & \text { Humanitarian Pedagogical Academy, Khmelnytskyi, Proskuriskoho Pidpillia str., 139, 29013, Ukraine, tel.: +3-8- }\end{aligned}$ 067-380-49-81, e-mail: mozoliev64@gmail.com

Open Access License: This is an open access article distributed under the terms of the Creative Commons Attribution-Non-Commercial-NoDerivatives 4.0 International (https://creativecommons.org/licenses/by-nc-nd/4.0/), which permits use, distribution, and reproduction in any medium, provided the original work is properly cited, the use is non-commercial and is otherwise in compliance with the license. 


\section{INTRODUCTION}

Analysis of scientific publications shows that over the last decade, the rate of decline in physical health of the younger generation has significantly accelerated. According to the Ministry of Health, nearly $90 \%$ of young people have various health disabilities. In their research, a number of scientists draw attention to the fact that over the past five years, the number of students exempted from physical education classes or transferred to special medical groups has increased by $40 \%$ [1]. The current level of requirements for the process of physical education of students in the higher education system requires, on the one hand, the use of health-improving training technologies, and on the other hand - improvement in students' motor abilities and functional resources. Successful completion of this task requires from the teacher a clear understanding of the initial level of students' physical fitness, their health status, development of functional systems of the body, presence of restrictions and contraindications [2, 3].

Monitoring of the university entrants' physical condition allows systematically obtaining the necessary information about the physical condition of young people who wish to study at a higher educational institution. It can be used to make decisions about staffing training groups, forming special medical groups for physical education classes [4]. Monitoring of the physical and functional state of a person is a complex of diagnostic studies that are conducted over a certain period of time [5, 6]. Monitoring gives an opportunity to determine changes in the physical development of a person, his or her functional state and health status, to make a comparative analysis of the correspondence of the individual level of development in accordance with the age and sex norm [7].

The method of rapid assessment is one of the most informative and acceptable in terms of practical use, when the level of health is determined by interpreting the quantitative indicators that characterize functioning of the most important life support systems [8]. Objective indicators of a person's physical condition include anthropometric indicators: measurement of the body weight and height; girth of the chest, neck, shoulder, hips, shin; respiratory rate; vital capacity of the lungs; heart rate, blood pressure. Subjective indicators of the person's physical condition include indicators of the health status, performance, sleep, appetite, mood.

The following hypothesis was postulated in the research: monitoring physical health of 16-17-year-old girls who become first-year students at Khmelnytskyi HumanitarianPedagogical Academy will allow teachers of physical culture to make timely adjustments in the organization of the educational process, to adequately respond to possible physical and morphofunctional deviations in the development of young people, which will eventually contribute to the goal of learning.

The goal is to monitor the physical health of 16-17-year-old girls who became first-year students at Khmelnytskyi Humanitarian-Pedagogical Academy in the period of 2016-2019.

Tasks:

- to study indicators of physical development of 16-17-year-old girls in the period of 2016-2019;

- to determine the level of development of morphofunctional resources and health status of 16-17-year-old girls;

- to ascertain the number of people who were exempted from physical education classes and the number of people with health disabilities who were referred to special medical groups;

- to carry out comparative analysis of the physical and functional development of 16-17-year-old girls who became first-year students at Khmelnytskyi HumanitarianPedagogical Academy in the period of 2016-2019. 


\section{MATERIAL AND METHODS}

Participants: 1,670 16-17-year-old female students who became first-year students at Khmelnytskyi Humanitarian-Pedagogical Academy in the period of 2016-2019 were involved in the study. In particular years the number of students was as follows: 2016 - 442 female students, 2017 - 426 female students, 2018 - 408 students, 2019 - 394 female students.

Methods: To obtain the necessary information, we used general scientific methods of the theoretical level of research, namely: analysis of scientific and methodical sources; a survey; a questionnaire; pedagogical observation; anthropometric, functional, and morphological methods; methods of mathematical statistics.

The analysis of scientific and methodological sources was used to study the current state of scientists' views on the problem of organizing physical education classes for 16-17-yearold students. Surveys and questionnaires were conducted in the course of determining the state of health and ascertaining deviations in the state of physical development and health of female students. Pedagogical observation was conducted as a purposeful systematic assessment of the physical and morphofunctional status of female students. In order to determine the indicators of physical development of first-year female students, anthropometric measurements were made that characterized the level of morphological features: body length (BL), body weight (BW), chest girth (ChG). Physiological research methods were used to evaluate the state of cardiovascular system: heart rate at rest (HR), systolic blood pressure (SBP), diastolic blood pressure (DBP); for the assessment of the respiratory system - vital capacity of the lungs (VC). Assessment of the students' physical health was performed by Apanasenko's method [4, 9, 10]. Persons with restrictions and contraindications to physical training classes were defined based on the provided certificates of medical institutions of Ukraine. The methods of mathematical statistics were used to accurately determine the morphofunctional resources and the health status of 16-17-year-old female students.

The research included the following stages:

1. determining persons assigned to the main, preparatory and special medical group and determining the number of female students exempted from attending physical education classes in the period of 2016-2019; interviewing students about the state of health and the opportunity to participate in the research;

2. establishing indicators of female students' physical development and conducting anthropometric measurements, including the body length (BL), the body weight (BW), and the chest girth (ChG);

3. determining functional indicators of the female students' physical condition: heart rate at rest (HR), systolic blood pressure (SBP), diastolic blood pressure (DBP), vital capacity of the lungs (VC);

4. determining the level of development of morphofunctional abilities and the health status of 16-17-year-old female students, which provided the results in the following indicators: life index (LI) - characterizes the functional capacity of the respiratory system; index of proportionality developmental (IPD) - characterizes the development of the chest; body mass index (BMI) - characterizes the assessment of conformity of the body weight to the height of a person; Robinson index (IR) - quantitative assessment of human energy potential; Ruffier-Dickson test (IRD) - characterizes physical performance of the heart

The results of the research proved the following major tendencies:

- increase in the number of female students exempted from physical education classes from $3.17 \%$ to $6.60 \%$;

- increase in the number of female students assigned due to the health state to special medical groups from $6.57 \%$ to $11.93 \%$; 
- decrease in the number of female students who study in the main group from $88.46 \%$ to $79.18 \%$

It should be noted that the processes of increasing numbers of female students who are exempted from physical education classes and transferred to special medical groups take place against the background of a decrease in the number of female students who entered the Academy in the studied period from 442 to 394 persons.

Table 1. Distribution of female students into groups for physical education classes $(n=1670)$

\begin{tabular}{ccccccccccc} 
Year of & $\begin{array}{l}\text { General } \\
\text { number } \\
\text { of female } \\
\text { entering }\end{array}$ & \multicolumn{2}{c}{ Main group } & \multicolumn{2}{c}{ Preparatory group } & \multicolumn{2}{c}{$\begin{array}{c}\text { Special medical } \\
\text { group }\end{array}$} & \multicolumn{3}{c}{$\begin{array}{c}\text { Exempted from } \\
\text { classes }\end{array}$} \\
\cline { 3 - 11 } & students & number & $\%$ & number & $\%$ & number & $\%$ & number & $\%$ \\
\hline 2016 & 442 & 391 & 88.46 & 8 & 1.81 & 29 & 6.57 & 14 & 3.17 \\
2017 & 426 & 366 & 85.91 & 7 & 1.64 & 36 & 8.45 & 17 & 3.99 \\
2018 & 408 & 334 & 81.86 & 11 & 2.69 & 41 & 10.05 & 22 & 5.39 \\
2019 & 394 & 312 & 79.18 & 9 & 2.28 & 47 & 11.93 & 26 & 6.60 \\
\hline
\end{tabular}

The study of indicators of physical development of female students and anthropometric measurements of the body length (BL), the body weight (BW) and the chest girth (ChG) are shown in Table 2 .

Table 2. Mean statistical indices of physical development of 16-17-year-old girls $(n=1670)$

\begin{tabular}{|c|c|c|c|c|c|c|c|c|}
\hline $\begin{array}{l}\text { Indicators } \\
\text { under } \\
\text { study }\end{array}$ & Year & $\mathrm{n}$ & $\bar{x}$ & $\mathrm{~S}$ & $\mathrm{Me}$ & $25 \%$ & $75 \%$ & $\mathrm{~V}[\%]$ \\
\hline \multirow{4}{*}{$\mathrm{BL}[\mathrm{cm}]$} & 2016 & 442 & 162.8 & 4.42 & 163.0 & 158.6 & 167.4 & 2.9 \\
\hline & 2017 & 426 & 163.4 & 4.81 & 163.5 & 158.7 & 168.3 & 3.1 \\
\hline & 2018 & 408 & 163.8 & 5.18 & 164.0 & 158.8 & 169.2 & 2.8 \\
\hline & 2019 & 394 & 163.3 & 4.87 & 163.5 & 158.6 & 168.4 & 2.9 \\
\hline \multirow{4}{*}{$\mathrm{BW}[\mathrm{cm}]$} & 2016 & 442 & 53.4 & 5.22 & 53.5 & 48.3 & 58.7 & 9.2 \\
\hline & 2017 & 426 & 53.9 & 5.41 & 54.0 & 48.6 & 59.4 & 10.1 \\
\hline & 2018 & 408 & 54.5 & 5.67 & 54.5 & 48.8 & 60.2 & 10.8 \\
\hline & 2019 & 394 & 54.8 & 5.96 & 55.0 & 49.0 & 60.9 & 11.7 \\
\hline \multirow{4}{*}{ ChG $[\mathrm{cm}]$} & 2016 & 442 & 72.6 & 6.82 & 72.5 & 65.7 & 79.3 & 6.9 \\
\hline & 2017 & 426 & 73.2 & 7.17 & 73.0 & 65.8 & 80.2 & 6.7 \\
\hline & 2018 & 408 & 73.4 & 7.38 & 73.5 & 66.1 & 80.9 & 7.3 \\
\hline & 2019 & 394 & 73.8 & 7.42 & 74.0 & 66.6 & 81.4 & 7.8 \\
\hline
\end{tabular}

Analysis of the statistical indices of physical development of 16-17-year-old girls showed that $82.3 \%$ of female students who became first-year students meet the standards of agerelated physical development.

The indices of body weight, height and body composition of the girls largely determine their level of health. The proper level of health is achieved due to the mandatory normalization of all components of body weight, which provides the necessary conditions for the normal course of metabolic processes for the harmonious functioning of the functional systems of the body. There is a general tendency towards a gradual increase in the body weight and volume of the girl's chest, which are still within the norm of age development. Analysis of the body mass index and anthropometric indices of 16-17-year-old girls showed that there is a tendency to an increase in the number of students with overweight from $9.2 \%$ to $11.7 \%(p<0.05)$, as well as in those who have $1-2$ degree of obesity from $1.2 \%$ to $1.7 \%$ $(p>0.05)$. 
Table 3. Functional indices of the physical condition of 16-17-year-old students ( $\mathrm{n}=1670)$.

\begin{tabular}{|c|c|c|c|c|c|c|c|c|}
\hline $\begin{array}{l}\text { Indices } \\
\text { under } \\
\text { study }\end{array}$ & Year & $n$ & $\bar{x}$ & $S$ & $\mathrm{Me}$ & $25 \%$ & $75 \%$ & $\mathrm{~V}[\%]$ \\
\hline \multirow{4}{*}{$\begin{array}{c}\mathrm{HR} \\
\text { [beats/ } \\
\text { min-1] }^{-1]}\end{array}$} & 2016 & 442 & 76.6 & 6.2 & 76.5 & 70.3 & 82.7 & 10.2 \\
\hline & 2017 & 426 & 77.4 & 7.6 & 77.5 & 69.9 & 85.1 & 10.8 \\
\hline & 2018 & 408 & 76.8 & 7.4 & 77.0 & 69.6 & 84.4 & 10.5 \\
\hline & 2019 & 394 & 77.8 & 8.2 & 78.0 & 69.8 & 86.2 & 11.3 \\
\hline \multirow{4}{*}{$\begin{array}{c}\text { SBP } \\
{[\mathrm{mmHg}]}\end{array}$} & 2016 & 442 & 117 & 5.5 & 117 & 110 & 123 & 5.6 \\
\hline & 2017 & 426 & 118 & 7.0 & 118 & 111 & 128 & 5.3 \\
\hline & 2018 & 408 & 117 & 7.0 & 117 & 111 & 128 & 4.9 \\
\hline & 2019 & 394 & 119 & 6.0 & 119 & 113 & 125 & 5.5 \\
\hline \multirow{4}{*}{$\begin{array}{c}\text { DBP } \\
{[\mathrm{mmHg}]}\end{array}$} & 2016 & 442 & 72 & 4.0 & 72 & 68 & 76 & 4.6 \\
\hline & 2017 & 426 & 74 & 5.0 & 74 & 69 & 79 & 4.4 \\
\hline & 2018 & 408 & 75 & 5.0 & 75 & 70 & 80 & 4.9 \\
\hline & 2019 & 394 & 75 & 4.0 & 75 & 71 & 79 & 5.2 \\
\hline \multirow{4}{*}{$\mathrm{VC}[\mathrm{ml}]$} & 2016 & 442 & 2860 & 100 & 2850 & 2750 & 2950 & 15.7 \\
\hline & 2017 & 426 & 2820 & 120 & 2820 & 2700 & 2940 & 16.8 \\
\hline & 2018 & 408 & 2800 & 110 & 2800 & 2690 & 2910 & 16.4 \\
\hline & 2019 & 394 & 2770 & 90 & 2770 & 2690 & 2870 & 17.1 \\
\hline
\end{tabular}

The results of our research showed that $78.2 \%$ of first-year female students had no deviation in the heart rate. Among $21.8 \%$ of female students who had deviations in HR, 106 girls $(6.38 \%)$ were enrolled to the special medical group, 51 girls $(3.05 \%)$ were exempted from physical education classes. In the course of our research, it was found that $9.32 \%$ of female students exceeded index of SBP, and $6.43 \%$ of girls had lower DBP. In general, HR and DBP indices of 16-17-year-old girls fluctuated within the normal range and did not significantly change during 2016-2017.

The results of the research showed that the index of VC in $34.8 \%$ of first-year female students was lower than the established norm, which indicates insufficient development of the respiratory system. The questioning of these female students proved that the vast majority of them led sedentary lifestyle and preferred working with the computer to active physical recreation. There is annual tendency to decrease the average VC index from 2860 $\mathrm{ml}$ to $2770 \mathrm{ml}$ of $16-17$ year old girls who became first-year students.

The analysis of average statistical data characterizing the level of development of morphofunctional resources and the health status of 16-17-year-old female students is presented in Table 4.

It is known that the standard of life index - LI for 16-17-year-old girls should be in the range of $50-55(\mathrm{ml} / \mathrm{kg})$. The results of our study determined that average statistical data is within normal limits. At the same time, there is a negative dynamics of the LI index, which is approaching the lower limit, indicating deterioration in the level of development of the respiratory system in 16-17-year-old girls, and, accordingly, in the overall physical development. The analysis of the average statistical data of the IPD and BMI indices shows that they are within the age norm of development of 16-17-year-old girls.

The analysis of the IR index proves that the average statistical data of the female student's energy potential are below the average and have the tendency to worsen. Among the female students involved in the research in 2016, only $21.2 \%$ had higher than average energy potential, and in $2019-17.1 \%$. The average level of energy potential was shown by $36.7 \%$ of the girls in 2016, and $31.8 \%$ in 2019 , respectively. 
The analysis of IRD shows that the index of physical performance of the heart of 16-17-yearold girls is near the middle and satisfactory levels of development and has negative dynamics during 2016-2019. There is an increase in the number of female students with a satisfactory IRD level from $32.2 \%$ in 2016 to $38.7 \%$ in 2019 and an increase in the number of female students with a low IRD level from $4.3 \%$ in 2016 to $6.5 \%$ in 2019.

Table 4. Morphofunctional indices of the health condition of 16-17-year-old female students $(\mathrm{n}=1438)$

\begin{tabular}{|c|c|c|c|c|c|c|c|c|}
\hline $\begin{array}{l}\text { Indices } \\
\text { under } \\
\text { study }\end{array}$ & Year & $n$ & $\bar{x}$ & $S$ & $\mathrm{Me}$ & $25 \%$ & $75 \%$ & V [\%] \\
\hline \multirow{4}{*}{$\begin{array}{c}\mathrm{LI} \\
{[\mathrm{ml} / \mathrm{kg}]}\end{array}$} & 2016 & 391 & 53.56 & 4.12 & 53.5 & 49.44 & 57.68 & 21.4 \\
\hline & 2017 & 366 & 52.32 & 4.33 & 52.2 & 47.99 & 56.65 & 22.7 \\
\hline & 2018 & 334 & 51.38 & 4.57 & 51.4 & 46.81 & 55.95 & 23.6 \\
\hline & 2019 & 312 & 50.55 & 4.68 & 50.6 & 45.87 & 55.23 & 24.2 \\
\hline \multirow{4}{*}{$\begin{array}{l}\text { IPD } \\
{[\%]}\end{array}$} & 2016 & 391 & 44.59 & 3.24 & 44.6 & 41.35 & 47.83 & 7.8 \\
\hline & 2017 & 366 & 44.80 & 3.65 & 44.8 & 41.15 & 48.45 & 7.6 \\
\hline & 2018 & 334 & 44.81 & 3.79 & 44.8 & 41.02 & 48.60 & 8.0 \\
\hline & 2019 & 312 & 45.19 & 3.57 & 45.2 & 41.59 & 48.73 & 7.8 \\
\hline \multirow{4}{*}{$\begin{array}{c}\mathrm{BMI} \\
{\left[\mathrm{kg} / \mathrm{m}^{2}\right]}\end{array}$} & 2016 & 391 & 20.07 & 1.77 & 20.0 & 18.30 & 21.84 & 5.9 \\
\hline & 2017 & 366 & 20.19 & 1.72 & 20.2 & 18.47 & 21.91 & 6.2 \\
\hline & 2018 & 334 & 20.26 & 1.83 & 20.3 & 18.43 & 22.09 & 6.4 \\
\hline & 2019 & 312 & 20.60 & 1.91 & 20.6 & 18.69 & 22.51 & 6.7 \\
\hline \multirow{4}{*}{$\begin{array}{c}\text { IR } \\
\text { [unit] }\end{array}$} & 2016 & 391 & 89.62 & 7.34 & 89.5 & 82.28 & 96.96 & 10.7 \\
\hline & 2017 & 366 & 91.33 & 7.85 & 91.2 & 83.43 & 99.18 & 11.2 \\
\hline & 2018 & 334 & 89.86 & 7.48 & 90.0 & 82.38 & 97.34 & 10.9 \\
\hline & 2019 & 312 & 92.58 & 7.92 & 92.6 & 84.66 & 100.5 & 11.7 \\
\hline \multirow{4}{*}{$\begin{array}{l}\text { IRD } \\
\text { [unit] }\end{array}$} & 2016 & 391 & 9.72 & 1.47 & 9.7 & 8.25 & 11.19 & 3.1 \\
\hline & 2017 & 366 & 9.98 & 1.61 & 10.0 & 8.37 & 11.59 & 3.4 \\
\hline & 2018 & 334 & 10.14 & 1.63 & 10.1 & 8.51 & 11.77 & 3.6 \\
\hline & 2019 & 312 & 10.26 & 1.77 & 10.3 & 8.49 & 12.03 & 3.7 \\
\hline
\end{tabular}

\section{DISCUSSION}

Health is the highest value to every person and determines their comprehensive and harmonious development. The problem of preserving young people's health is an urgent issue for the society, as it is an indicator of the country's civilization. Today, health is not regarded as a purely medical problem; it covers a much broader range of issues, based on anthropometric, physiometric, and morphofunctional features.

Professor H.L. Apanasenko developed and validated a method for quantitative express assessment of the level of somatic health $[9,10]$. It is based on anthropometric (height, body weight) and physiometric (lung volume, heart rate, hand strength, systolic pressure) parameters. He believes that somatic human health can be estimated by the total amount of the body's energy potential.

The majority of researchers examine the peculiarities of physical development using anthropometry and define the following methods for assessing students' somatic health: anthropometric standards, correlations, and indices [11-15].

Solving the problem of monitoring the physical health of students and engaging them in physical exercises is considered by the researchers in the following planes: 
- $\quad$ proving the efficiency and popularization of modern varieties of fitness lessons $[16,17]$;

- motivation of young people to maintain their health and the vital need for regular sports activities [18];

- carrying out changes of directions of training in preparation of specialists in the sphere of physical culture and sports, recreation and physical rehabilitation [19];

- development of interest of young people in sports and dissemination of game methods in conducting classes, organization of leisure and physical recreation [20].

The analysis of the obtained results of our research confirms the priority in the importance of physical state of health in the system of motives for physical education [6, 11]. Based on the results of our study, the data of some scientists on the methods of monitoring the physical condition of first-year female students was expanded [4, 10,14]. The conducted research confirmed and expanded the scientific views of many researchers on the need for a systematic assessment of the level of physical health and the functional status of students at each stage of study, which will allow making timely changes and adjustments of curricula $[1,7]$.

\section{CONCLUSIONS}

1. The results of the research have found that during 2016-2019 there was a tendency to increase the number of female students exempted from physical education classes from $3.17 \%$ to $6.60 \%$ and to increase the number of female students who were assigned to special medical groups for physical education classes for health reasons from $6.57 \%$ to $11.93 \%$.

2. The analysis of statistical indices of physical development of 16-17-year-old girls showed that $82.3 \%$ of female students who became first-year students meet the standards of age-related physical development. The analysis of changes in anthropometric indices of girls showed that there was a tendency to increase the number of female students with overweight from $9.2 \%$ to $11.7 \%$, as well as those who had $1-2$ degree of obesity from $1.2 \%$ to $1.7 \%$.

3. The results of the analysis of the functional indices of the physical condition of 16-17-year-old female students showed that $21.8 \%$ of female students had deviations in the age-related heart rate, and the index of vital capacity of lungs in $34.8 \%$ of first-year students was lower than the established norm.

4. The analysis of the Robinson index shows that the average statistical data of the female students' energy potential was below the average and tended to worsen. The analysis of the Ruffier-Dickson test shows that the index of physical performance of the heart of 16-17-year-old girls was near the middle and satisfactory levels of development and had negative dynamics during 2016-2019.

\section{REFERENCES}

[1] Blagiy OL, Yachnyuk MYu. Analysis of indicators of physical condition of student youth. Bulletin of Chernihiv National Taras Shevchenko University. Physical Education and Sports. 2015;129(3):27-32.

[2] Mozolev O, Bloshchynskyi I, Alieksieiev O, et al. Influence of modern fitness technologies on the state of health and development of motor abilities of 17-19-year-old female students. J Phys Educ Sport. 2019;3:917-924.

[3] Zhamardiy V, Shkola O, Okhrimenko I, et al. Checking of the methodical system efficiency of fitness technologies application in students' physical education. Wiadomości Lekarskie. 2020;73(2):332-341. https://doi.org/10.36740/ WLek202002125

[4] Krutsevych TYu, Vorobiov MI, Bezverkhnia MM. Control in the physical education of children, adolescents and youth: Training Manual. Olympic Literature, 2011. 
[5] Kemin O. Assessment of the level of somatic health of the 9 form pupils and the factors of negative influence on it. Physical Education, Sport and Culture of Health in Modern Society: Collection of scientific works. 2015;2(30):70-73.

[6] Korol SA. Evaluation of the state of somatic health and physical training of the first course students of technical specialties. Pedagogy, Psychology and Medical-Biological Problems of Physical Education and Sports. 2014;11:23-29. https://doi.org/10.15561/18189172.2014.1105

[7] Makarova LN, Romashevska NI. Integral assessment of physical condition of schoolchildren during physical education classes. Int Sci J. 2017;58(4):34-38.

[8] Leuciuc F. Effect of a one-semester conditioning activities on physical fitness of the students. Revista Romaneasca pentru Educatie Multidimensionala. 2019;11(4):136-146. https://doi.org/10.18662/rrem/162

[9] Apanasenko HL. On the possibility of quantitative assessment of the level of human health. Hygiene and Sanitation. 1985;6:55-58.

[10] Apanasenko HL. Individual health: Theory and practice. introduction to the theory of individual health. Kiev: Medkniga, 2011.

[11] Blavt OZ. Informative indices of the level of physical health and physical fitness of university students. Pedagogy, Psychology and Medical-Biological Problems of Physical Education and Sports. 2012;11:14-18.

[12] Huba VP. Scientific-Practical and Methodological Foundations of Physical Education of Young People. Textbook. Moscow: Soviet Sport, 2008.

[13] Turchyna NI. Research on students' health and level of physical development. Pedagogy, Psychology and MedicalBiological Problems of Physical Education and Sports. 2010;12:150-152.

[14] Fomenko EV. Comparative analysis of physical fitness and motor-coordinating abilities of the first and second year students of higher pedagogical educational institutions involved in aerobics. Pedagogy, Psychology and MedicalBiological Problems of Physical Education and Sports. 2014;3:75-78.

[15] Wengerova NN. Stretching as a means of somatic health changing of female university students aged 17-18. Scientific notes of the University P.F. Leshafta. 2009;4(50):29-33.

[16] Kashuba V, Kolos M, Rudnytskyi O, et al. Modern approaches to improving body constitution of female students within physical education classes. J Phys Educ Sport. 2017;17(4):2472-2476.

[17] Usachov Yu. Peculiarities of morphofunctional state of girls engaged in health fitness. Theory and Methods of Physical Education and Sports. 2007;3,86-89.

[18] Prontenko K, Griban G, Medvedeva I, et al. Interrelation of students' motivation for physical education and their physical fitness level. Int J Appl Exerc Physiol. 2019;8(21):896-907. https://doi.org/10.30472/ijaep.v8i2.1.566

[19] Mozolev O, Halus O, Bloshchynskyi I, Kovalchuk R. Human resources management of educational development in sphere of physical culture and sports in Ukraine: Comparative analysis (1992- 2016). J Phys Educ Sport. 2019;1:185192.

[20] Bloshchynskyi I, Kovalchuk R, Balendr A, et al. Conceptual basis of organization of volleyball team training. Int J Appl Exerc Physiol. 2019;8(2):1-12. https://doi.org/10.30472/ijaep.v8i2.430 